\section{KEY FOR EXTRACTING THE TEETH.}

\section{To the Editor of The LANCET.}

SrR :-Having made improvements on the the key-instrument for extracting teeth, I wish to place before your readers an explanation of its construction and advantages. It consists of an oblong bolster, lever, shaft, handle, and claws. The shaft and handle resemble those of the other keys.

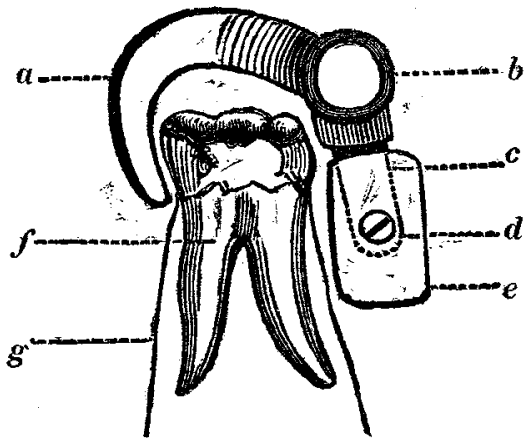

This plate represents the end of the instrument when adjusted for extraction. a, the claw; $b$, the head of the claw-screw; $c$, dotted lines showing the direction of the lever within the bolster; $d$, the head of the plate, or bolster-screw ; $e$, the bolster, with its smooth surface towards the tooth ; $f$, the tooth; $g$, the alveolar process.

The smooth surface of the bolster is to be applied naked to the gum; the claw is then to be turned over, and placed on the opposite side of the neck of the tooth, using the same motion of the hand and wrist as is employed with the other keys for extraction.

The advantages are, that it occupies less room in the mouth than the other keys, being used without a pledget or pad of any description; and the gums are not injured by its action. Owing to the firm and steady pressure of the surface of the bolster against the gum, and the length and ascending motion of the lever, the tooth is lifted perpendicularly from its socket. It is generally applicable to all descriptions of teeth.

The qualities that I have attributed to it, are drawn from the results of many hundred experiments performed on various teeth. I remain, Sir, your obedient servant,

R. O. Millett.

Hayle, Cornwall, Nov. 23, 1837.

\section{CRANIAL BLOOD-SWELLINGS.}

To the Editor of The LANcET.

Sir:-In your Number for Nov. 25, there are some remarks of interest upon cranial swellings, by Mr. Wagstaffe; I cannot, however, agree with that gentleman in believing they occur" without being " the result of violence or parturition." Some years ago the subject considerably interested my friend $\mathrm{Mr}$. Callaway and myself, and in three cases we distinctly traced each to have been the result of accidental blows after birth. The swellings which appear to cccur spon. taneously soon after the birth of a child, I have been disposed to think, arise from the rupture of some vessel whilst the bones are overlapping each other during the process of parturition. The treatment recommended by Mr. Wagstaffe I consider very desirable, and I certainly should look upon opening these tumours as injudicious; at the same time, if the removal of the blood is not urged by proper measures, the bone does undergo a change from pressure, and may be productive of mischief; a specimen illustrative of this fact $I$ possess, and shall be happy to show it $\mathrm{Mr}$. W., or any gentle. man interested in the subject. I remain yours, \&c.

Newington, Dec. 20, 1837.

W. T. ILIFF.

\section{LITHOTRITY.}

REPLY OF MR, JEATFRESON TO MR. DENHAM,

\section{To the Editor of The Lancet.}

SrR :-In reply to the criticism of Mr. Wm. Hempson Denham, on my unsuccessful cases of lithotrity, I beg to state, that when Mr. Costello dismissed his patient, Smith, from town, he gave him the most judicious and scientific directions to prevent relapse; and it is only from Mr. Denham's extensive experience that we learn that future lithic deposit can be certainly prevented. The only reason why lithotrity was resorted to in this case was, that the patient would not submit to lithotomy.

Had Mr. Denham seen or examined Mr. Costello's urethral forceps, he would have had no difficulty in perceiving that the blades of that instrument might become so embedded in the substance of a fragment of a calculus, composed principally of phosphate of lime, as to prevent their expansion, and render futile any effort to disengage them.

To convince Mr.Denham that he might be mistaken in his prognostic of a fatal result in a case of lithotomy, accompanied by muco-purulent discharge from the bladder, I will mention that, many years since, Mr. King, of Saxmundham, lithotomised a patient who had so much of this discharge as to induce one of the surgeons of the Norwich Hospital to refuse to perform the operation, yet this person perfectly recovered. In these sad cases the decision must be left to the patient, whether he will submit to the only means which can give him a chance 
of recovery, or linger out a miserably pain ful existence. I claimed nothing original in the report of these cases, but simply wished to put my professional brethren in possession of some of the difficulties which I had experienced, in order that they might be prepared, should similar cases occur in their own practice; and $I$ felt this to be the more imperative, because the published cases of lithotrity give us only the bright side of the picture. I am, Sir, yours respectfully,

\section{W, Jeaffaeson.}

Framlingham, Dec. 23, 1837.

\section{ELOCUTION OF LECTURERS.}

\section{To the Editor of The LanceT.}

SIR:-The just and fearless manner in which The LANCET has ever been devoted to the advancement of medical education, induce me to hope that you will continue to give your attention to the Medical School of University College. The nomination to the chairs in this School is entirely in the hands of the Council, and it gives me great pleasure to bear evidence to the fact that the majority of them are filled quite to the satisfaction of the students. Those, however, who recollect Professor Turner, feel that, in the department of chemistry, there is now a disadvantage experienced which, I fear, in the present Professor, cannot be amended. Whilst I, with all others, admit that he is well-informed in his subject, and thus far highly qualified for the appointment, I cannot hesitate to say that he is deficient in one essential at least, which is, perhaps, more necessary than even profound chemical research itself. In France, and throughout Germany, a clear and distinct enunciation, and a capacity for imparting information, are considered to be indispensable qualifications in a professor. In these points Professor Graham is exceedingly defective. He is by birth, and early association, so inveterately Scotch in his accent, as to be often unintelligible to his English auditors.

I endeavour to get as near as possible to him at lecture, yet I, day after day, leave the theatre uninformed on matters on which he discourses, as I am never able to follow him through a sentence of any length. I wish it to be clearly understood, that I do not, in this, mean any personal disrespect to Professor Graham. The error is one, however, which should have been prevented at the time of the appointment of the late Professor Turner's successor. I am, Sir, your obedient servant,

A Student of University College.
NEW EXAMINATIONS AT THE LONDON

COLLEGE OF SURGEONS.

\section{To the Editor of THE LANCET.}

SIR :-I have no doubt that the following observations will be gratefully received by a large body of your readers on the other side of the channel, if you can find room for them in the pages of your valuable Journal.

Having recently undergone the ordeal to which the refer, I can speak from experience on the subject; and also having felt the want of information respecting the said examination, previous to the arrival of the very day itself. The same want, $I$ know, is felt by many of my brethren in the Green Isle, more especially since the late change from the old routine of examination.

Prior to May last, only one candidate was examined at a time at the above College, and the examination was of only half its present duration. Now there are three candidates examined together. The Court of Examiners, being twelve in number, is now divided into three bodies, each of which occupies a separate table in the Examination Hall, and one candidate is examined by each of those divisions. After being examined by the first division, for at least twenty minutes, a bell rings, and the candidate is passed on to the next division, when he is examined during the same length of time, and so on until he passes the fourth division; the entire examination thus continuing for one hour and twenty minutes. The candidate then retires, and is not informed (as was formerly the case) whether he has passed or not, until the entire number of candidates is examined. The Examiners then compare notes, and decide the fate of those who are in suspense. The examinations are, therefore, much more strict than they were; as a proof of which, suffice it to say, that, within the last three weeks, no less than seven candidates have been rejected, and two of these were Edinburgh PHYsICIANS, being totally deficient in anatomy. The Examiners state, that they find that the Irish candidates, though gaod anatomists, are very deficient in physiology. For instance, after I had passed, Sir B. Brodie told me to read "Magendie's Physiology" more attentively than I had done, and said, "How is it that ye Irish are such good anatomists and such bad physiologists?" The bones are now produced on the tables. Yours, \&c.

A Fresh Surgeon. 